\title{
Researches on evaluation of smooth entrance in cutting using electrical current. A case study
}

\author{
Valentin Diţu ${ }^{1}$, Gheorghe Oancea ${ }^{1}$, Raluca Daicu ${ }^{1, *}$ \\ ${ }^{1}$ Transilvania University of Brașov, Department of Manufacturing Engineering, Mihai Viteazu No.5, \\ Braşov, Romania
}

\begin{abstract}
At metal drilling, at the beginning of the process, the cutting tool in the chisel edge zone, frictions and plastically deforms the material, and then enters in cutting. If the drill is entered smoothly in cutting with a special device, its life is increased. The paper presents how the electrical current at cutting is used for the evaluation of smooth entrance in cutting in comparison with classical cutting. These are demonstrated for $41 \mathrm{MoC} 11$ steel drilled with a set of 30 tools having $8 \mathrm{~mm}$ diameter.
\end{abstract}

\section{Introduction}

The drill is the cutting tool that works in the most severe conditions comparatively with the other cutting tools because:

- the cutting speed varies from zero in the center of drill to the maximum value at the exterior diameter;

- due to the functional clearance angle, that has the zero value from a diameter of approximate $0.3 \mathrm{~mm}$, the drill cannot cut up to its axis;

- the resulted heat at drilling is concentrated in great proportion (minimum 40\%) in the cutting tool.

These reasons motivate taking any measures that can increase the tool life. One of these measures is the smooth entrance in cutting.

Smooth entrance in cutting is considered, at drilling, when at a certain diameter of the drill, the cutting force is equal with the cutting resistance, the chip is in balance and the vibrations are damped. At a certain diameter of the hole, the minimum axial force needed for cutting depends, when the other parameters are constant, on the ratio between the cutting lip and the chisel edge. If the material is not homogenous, then the axial feed should depend on the material hardness, but the cutting feed is constant at ordinary processes, fact that leads to variable cutting forces and vibrations, due to the material hardness variations. If the vibrations are damped, then the tool life of the drill increases [1].

\footnotetext{
*Corresponding author: raluca.daicu@unitbv.ro
} 


\section{Efficiency appreciation of drill smooth entrance in cutting}

It is known that the state of a cutting edge can be appreciated by the value of cutting electrical current voltage [2-8]. The higher this value is, the higher the initial temperature is $[9,10]$, due to the imperfections of the cutting edge.

In this section it is analyzed the value of the electrical current for classical drilling and for drilling with smooth entrance in cutting.

There were purchased 30 drills with $\Phi 8 \mathrm{~mm}$ diameter, the cutting edge material being HS 6-5-2 steel. To decrease the necessary time for the experiments, the drilling was done on the $41 \mathrm{MoC} 11$ steel (tensile strength $-950 \mathrm{MPa}$ ), with the 6GCODA1 drilling machine.

The electrical current at cutting was measured with the experimental stand from figure 1 for classical drilling, where 1- mandrel for fixing the drill, 2 - collector brushes, 3 measuring instrument for electrical current voltage at cutting, and with the experimental stand from figure 2 for smooth entrance in cutting.

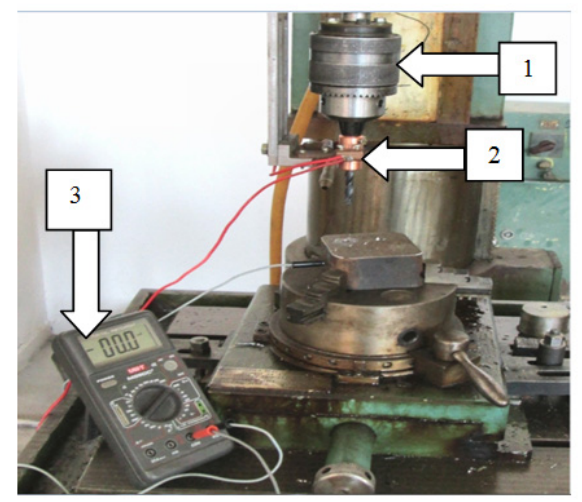

Fig. 1. Experimental stand used in measuring process of the electrical current at classical drilling.

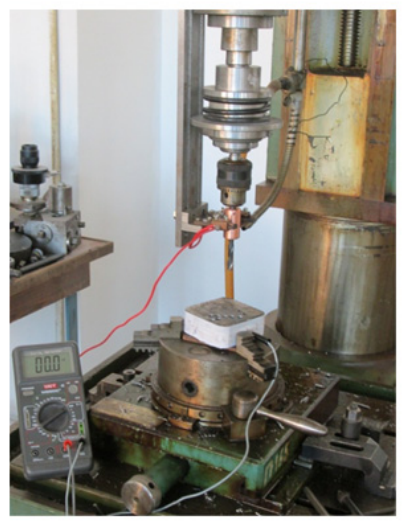

a) Experimental stand for smooth entrance in cutting

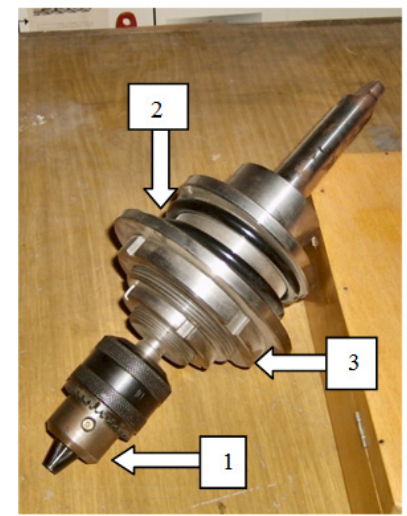

b) Device for smooth entrance in cutting

Fig. 2. Experimental stand used in measuring process of the electrical current at drilling with smooth entrance in cutting.

The device for smooth entrance in cutting (fig. $2, \mathrm{~b}$ ) has the next main elements: 1 mandrel for fixing the drill, 2 - compression arc, 3 - element for adjusting the compression arc.

There were examined at microscope the edges of each drill in order to find manufacturing defects and to explain the value of the cutting electrical current voltage. 
For a drill there were visualized the cutting lips (two) and the chisel edge identifying if they have defects or not.

In researches, the sequence of the experimental steps was the following: microscope visualization, - taking the decision about drill quality, - measuring the electrical current at normal drilling, - taking the decision about drill quality based on the voltage value of the electrical current at cutting, - measuring the electrical current at drilling with smooth entrance in cutting and establishing the final conclusion.

To measure the values of the electrical current the following cutting parameters were used: $\mathrm{s}=14.07 \mathrm{~m} / \mathrm{min} ; \mathrm{f}=0.25 \mathrm{~mm} / \mathrm{rev} ; \mathrm{a}=\mathrm{D} / 2=4 \mathrm{~mm}$. Also the axial cutting force was estimated $\left(F_{x}=2560 \mathrm{~N}\right)$, according to [11], in order to adjust the device for smooth entrance in cutting.

In Table 1 there were centralized the obtained results for the electrical current at cutting for normal drilling and for drilling with smooth entrance in cutting, for the considered drills.

Table 1. Obtained values for cutting electrical current voltage at drilling $41 \mathrm{MoC} 11$ steel, classically and with smooth entrance in cutting.

\begin{tabular}{|c|c|c|c|c|c|c|}
\hline $\begin{array}{l}\text { No. of } \\
\text { drill }\end{array}$ & $\begin{array}{c}\text { Drill } \\
\text { diameter } \\
{[\mathrm{mm}]}\end{array}$ & $\begin{array}{c}\text { Spindle } \\
\text { speed } \\
\text { [rev/min] }\end{array}$ & $\begin{array}{c}\text { Cutting } \\
\text { speed } \\
{[\mathrm{m} / \mathrm{min}]}\end{array}$ & $\begin{array}{c}\text { Feed } \\
{[\mathrm{mm} / \mathrm{rev}]}\end{array}$ & $\begin{array}{c}\text { Voltage“ } \mathrm{U}_{0} " \\
\text { of electrical } \\
\text { current at } \\
\text { normal } \\
\text { drilling }[\mathrm{mV}]\end{array}$ & $\begin{array}{c}\text { Voltage "U," } \\
\text { of electrical } \\
\text { current for } \\
\text { smooth } \\
\text { entrance in } \\
\text { cutting } \\
\text { [mV] }\end{array}$ \\
\hline 1 & \multirow{30}{*}{8} & \multirow{30}{*}{560} & \multirow{30}{*}{14.07} & \multirow{30}{*}{0.25} & 0.5 & 0.3 \\
\hline 2 & & & & & 0.5 & 0.4 \\
\hline 3 & & & & & 0.4 & 0.3 \\
\hline 4 & & & & & 0.3 & 0.2 \\
\hline 5 & & & & & 0.3 & 0.3 \\
\hline 6 & & & & & 0.6 & 0.4 \\
\hline 7 & & & & & 0.2 & 0.1 \\
\hline 8 & & & & & 0.3 & 0.2 \\
\hline 9 & & & & & 0.4 & 0.3 \\
\hline 10 & & & & & 0.2 & 0.1 \\
\hline 11 & & & & & 0.4 & 0.2 \\
\hline 12 & & & & & 0.4 & 0.2 \\
\hline 13 & & & & & 0.5 & 0.3 \\
\hline 14 & & & & & 0.6 & 0.3 \\
\hline 15 & & & & & 0.6 & 0.6 \\
\hline 16 & & & & & 0.5 & 0.4 \\
\hline 17 & & & & & 0.3 & 0.2 \\
\hline 18 & & & & & 0.2 & 0.1 \\
\hline 19 & & & & & 0.2 & 0.1 \\
\hline 20 & & & & & 0.6 & 0.4 \\
\hline 21 & & & & & 0.4 & 0.3 \\
\hline 22 & & & & & 0.4 & 0.3 \\
\hline 23 & & & & & 0.6 & 0.4 \\
\hline 24 & & & & & 0.8 & 0.5 \\
\hline 25 & & & & & 0.4 & 0.2 \\
\hline 26 & & & & & 0.7 & 0.5 \\
\hline 27 & & & & & 0.6 & 0.4 \\
\hline 28 & & & & & 0.6 & 0.5 \\
\hline 29 & & & & & 0.5 & 0.4 \\
\hline 30 & & & & & 0.6 & 0.6 \\
\hline
\end{tabular}


Based on the obtained results the drills were grouped in 3 categories:

- drills quality I : $\mathrm{U}_{0}=0.1 \div 0.3 \mathrm{mV}-7$ pieces

- drills quality II : $\mathrm{U}_{0}=0.4 \div 0.5 \mathrm{mV}-13$ pieces

- drills quality III : $\mathrm{U}_{0}=0.6 \div 0.8 \mathrm{mV}-10$ pieces

The data from Table 1 is graphically represented in Figures 3 and 4.

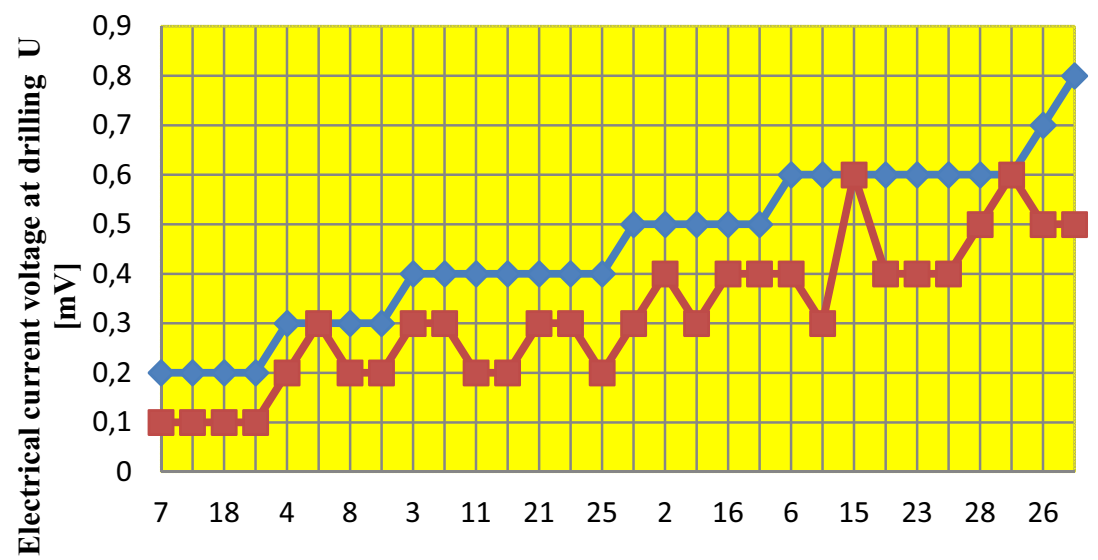

No. drill

$\neg$ Classical drilling $=$ Drilling with smooth entrance

Fig. 3. Electrical current variation in ascending order of voltage.

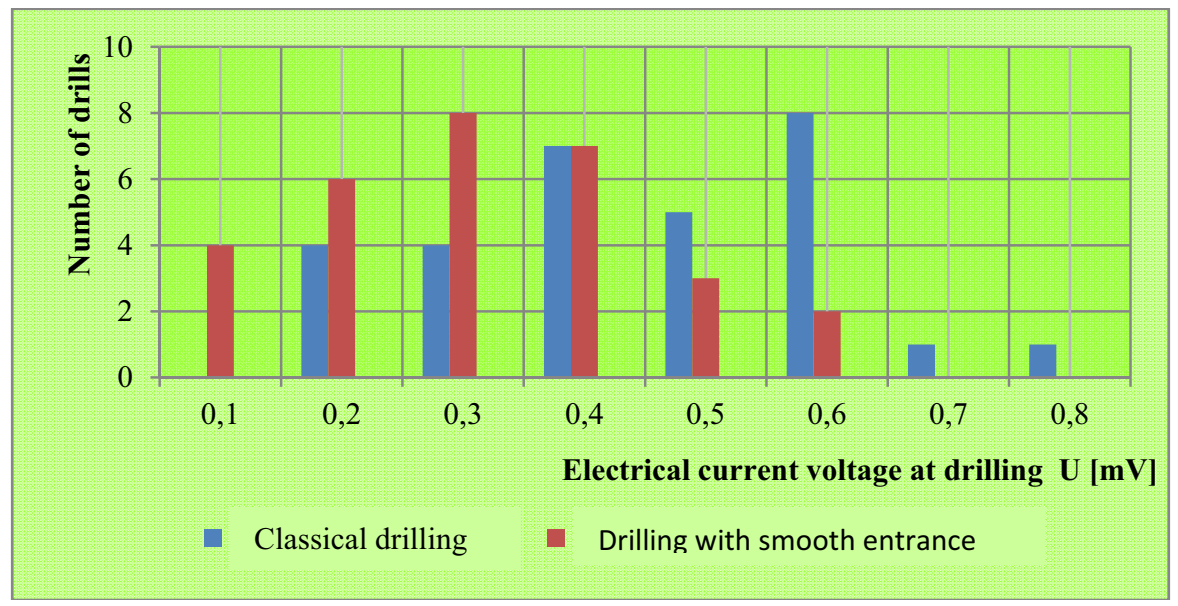

Fig. 4. Number of drills at the same value of electrical current at cutting.

The graphics presented in Figures 3 and 4 clearly show the fact that at smooth entrance of drill in cutting the voltage of the electrical current at cutting decreases, the temperature in the cutting zone also decreases, resulting the increasing of tool life.

There were observed 3 exceptions for drills no. 5, 15 and 30 for which the smooth entrance did not modify the value of the cutting electrical current voltage. To identify the reason for these exceptions, in Figures 5, 6, 7 and 8 are presented the cutting lip and chisel edges of drills no. 5 and no. 30 before normal cutting and after processing $10 \mathrm{~mm}$ hole length when the smooth cutting began. 


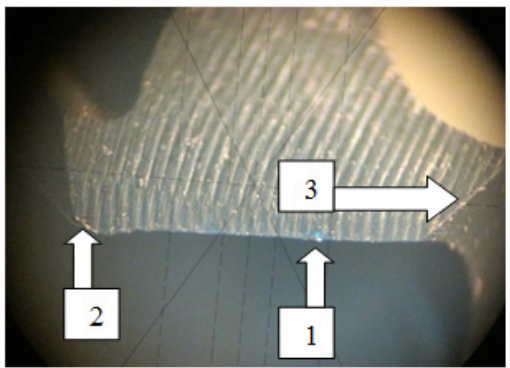

a) First edge

Fig. 5. Drill no. 5 at beginning of normal cutting.

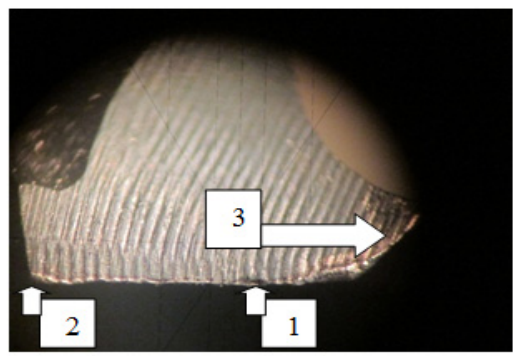

a) First edge

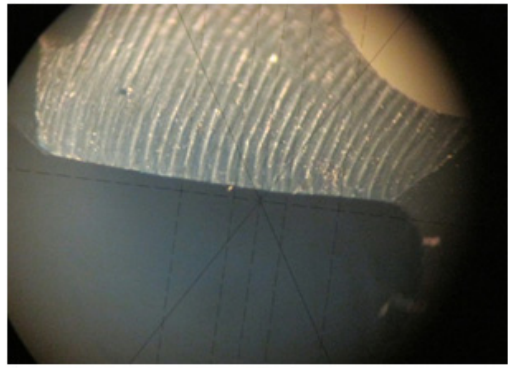

b) Second edge

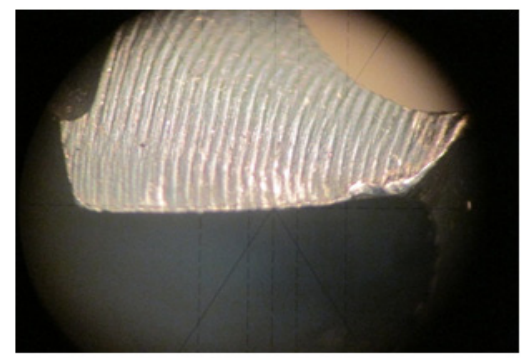

b) Second edge

Fig. 6. Drill no. 5 at beginning of smooth entrance in cutting.

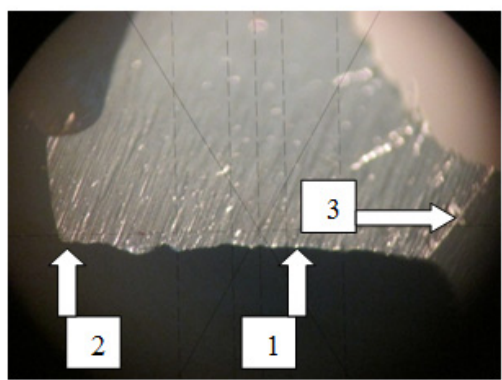

a) First edge

Fig. 7. Drill no. 30 at beginning of normal cutting.

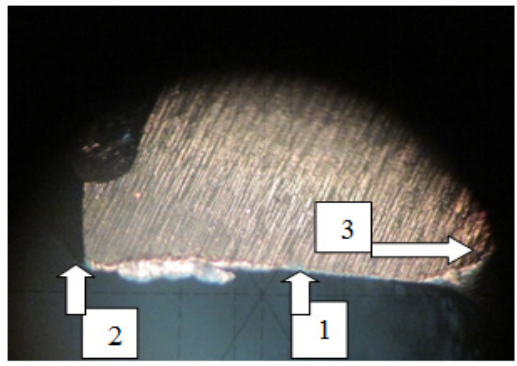

a) First edge

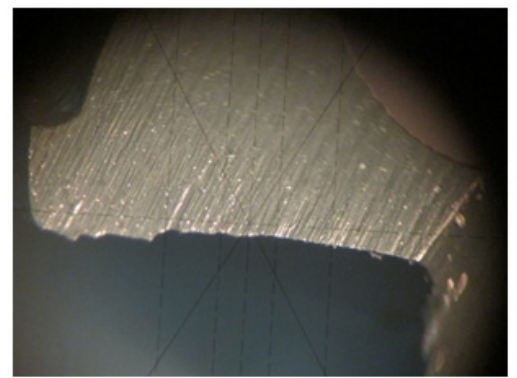

b) Second edge

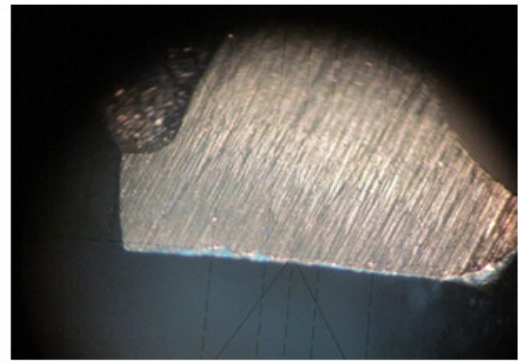

b) Second edge

Fig. 8. Drill no. 30 at beginning of smooth entrance in cutting.

In case of drill no. 5 it can be observed that it was correctly sharpened but due to the improper roughness obtained at sharpening with a coarse-grained abrasive wheel, after 10 $\mathrm{mm}$ hole length it was intense worn out especially in the chisel edge zone (3). 
Drills 15 and 30 present similar characteristics. The cutting lips (1) are not properly sharpened and the chisel edge (3), at the intersection with the cutting lip (1) it is not well sharpened, reasons for which the drills were intense worn out, especially at the cutting lip zone.

For the three analyzed tools, their smooth entrance in cutting led to decrease of the temperature in the cutting zone, but the wear in the transversal edge zone has contributed to increase of the temperature, fact that had as consequence the obtaining of same values for the electrical current voltage.

\section{Conclusion}

Based on the researches conducted by the authors it can be concluded that the electrical current at cutting process can be used to evaluate the smooth entrance in cutting. These are demonstrated for the drilling process using a set of 30 drills with $8 \mathrm{~mm}$ diameter and $41 \mathrm{MoC} 11$ steel like for parts material.

Due to the experiments, it is easy to observe that the smooth entrance in cutting of drills contributes to increase of their life by decreasing the temperature in the cutting zone; in this case the cutting develops at the equality between the cutting resistance of the material and the cutting force; also it takes place a vibration damping. Measuring accurately the electrical current at cutting demonstrates the advantages of smooth entrance in cutting of the drill.

\section{References}

1. V. Diţu, TEHNOMUS, 264 (1987)

2. V. Diţu, AJME 1, 63 (2008)

3. H. Bagchi, S.K. Basu, Wear 26, 39 (1973)

4. V. Diţu, WSEAS 2, 322 (2009)

5. A.L. Plotnikov, E.G. Krylov, E.M. Frolov STIN 1, 2 (2009)

6. M. Murata, S. Kurokawa, O. Ohnishi, CSME 79, 2546 (2013)

7. M. Murata, S. Kurokawa, O. Ohnishi, M. Uneda, T. Doi, CSME 6, 958 (2012)

8. H. Hirota, M. Murata, A. Kojima, K. Yanagihara, JSPE 64, 1191 (1998)

9. V. Diţu, AJME 8, 18 (2010)

10. R. Tanaka, A. Hosokawa, K. Yamada, T. Ueda, Proceedings of the Seventh International Conference on Progress of Machining Technology, 786 (2004)

11. A. Vlase, Cutting parameters, cutting allowances and technical time standards (Technical Publishing House, Bucuresti,1983) 